\title{
Корреспонденции не вручены адресату
}

\author{
С. В. Федотов ${ }^{凶}$, В. И. Федотов \\ Воронежский государственный университет, Российская Федераиия \\ (394018, г. Воронеж, Университетская пл., 1)
}

\begin{abstract}
Аннотация: Цель статьи - познакомить российскую географическую общественность с новыми биографическими материалами о взаимоотношениях профессора Ф.Н. Милькова и некоторых известных отечественных географов. 15 октября 2021 года исполнилось четверть века со дня смерти профессора Ф.Н. Милькова. Авторами статьи использованы достоверные источники, хранившиеся в личном архиве профессора: многолетняя переписка с сотрудниками Института географии АН СССР/PAН Л.С. Абрамовым и Э.М. Мурзаевым, первым аспирантом и коллегой по кафедре в 60-х годах Г.Е. Гришанковым, эпизодические контакты с профессором В. И. Булатовым. Представленная в статье информация публикуется впервые.

Жизненный опыт творцов науки показывает, когда создаются нереальные условия прямого контактного общения, то активно используется эпистолярный стиль. Почтовые отправления остаются единственным фондом в архивах ученых, где хранятся достоверные материалы их личных взаимоотношений. Ф.Н. Мильков в течение многих лет вел переписку со многими известными отечественными географами. Настоящая статья акцентирует внимание на четырех авторах корреспонденций, которые не были вручены адресату в связи с его смертью.
\end{abstract}

Ключевые слова: корреспонденции, письма, телеграмма, монография, учебное пособие, коллеги, институт.

Для цитирования: Федотов С. В., Федотов В. И. Корреспонденции не вручены адресату // Вестник Воронежского государственного университета. Серия: География. Геоэкология, 2021, № 4, с. 126-134. DOI: https://doi.org/10.17308/geo.2021.4/3761

Информация о скоропостижной кончине профессора Ф.Н. Милькова не сразу стала известна географической общественности страны. Основные авторитетные периодические географические издания откликнулись некрологами только в следующем году после его смерти - «Известия РАН. Серия географическая», 1997, № 2; «Известия Русского Географического общества», 1997, т. 129, вып. 3; «Вестник Московского университета. Серия 5. География», 1997, № 3; «География в школе», 1997, № 2.

А пока до конца 1996 года в адрес профессора Ф.Н. Милькова шли письма, телеграммы, открытки. Нам из личного архива Федора Николаевича известно пятеро корреспондентов, с почтовыми отправлениями которых он не смог познакомиться - Л.С. Абрамов, В.И. Булатов, Г. Е. Гришанков, Э. М. Мурзаев, В. С. Преображенский.

(С) Федотов С.В., Федотов В.И., 2021

$\checkmark$ Федотов Сергей Владимирович, e-mail: fsv777@yandex.ru

\section{Л.С. Абрамов - любезный друг!}

Абрамов Лев Соломонович (1915-2005) - уроженец города Дмитрова Московской губернии. Выпускник географического факультета МГУ (1941). С 1942 по 1952 год занимал офицерские должности в Советской армии. Восемь лет (19521960) работал редактором научно-популярного журнала «Природа». С 1960 года и до кончины сотрудник Института географии АН СССР/PAН, где долгое время исполнял обязанности заместителя главного редактора журнала «Известия Академии наук. Серия географическая». Основные научные интересы связаны с историей географической (академической) науки и общими вопросами физической географии.

Первое знакомство с Ф.Н. Мильковым у Абрамова, очевидно, состоялось во время его работы в журнале «Природа». Профессор Ф.Н. Мильков несколько раз публиковал свои короткие заметки в 
журнале, когда там редактором работал Лев Соломонович - 1953, дважды в 1954, 1955 и 1958 годах.

В архиве Федора Николаевича сохранилось короткое письмо (по-видимому, одно из первых) Л. С. Абрамова в Воронеж, датируемое 1956 годом. Письмо короткое и выдержано в сдержанных интеллигентных тонах.

\section{Дорогой Федор Николаевич!}

Прежде всего 1000 извинений за долгое молчание. Был очень занят и хворал. Сердечно благодарю Вас за Вашу книгу о Краснове. Еще до ее получения познакомился с этой интересной фигурой. И я не пожалел, что сочувственно отнесся к Ваиим планам в этом отношении. Что касается до «Очерков истории развития географии», то тема эта весьма обширна, если не скользить по поверхности. Не думаю, что ее кто-либо разрабатывал в изелом. Вместе с тем несомненно, что по отдельным областям знания исследования ведутся на местах и вероятно в значительном количестве, с использованием архивных материалов и т.n. Это следует учитьвать.

С интересом жду Вашего учебника по географии СССР, часть I-я. Очевидно, он должен собой заменить Добрынинский, написанный на очень невысоком уровне. Желаю Вам всяческих успехов на этом поприще. Хорошая, написанная на высоком уровне книга о СССР имеет выдаюшееся значение не только для студенчества, но и для понимания «наверху» выдаюшегося значения физ. [ической] географии и в теоретическ. [ом] и практическом отношении.

С искренним приветом Ваш Абрамов 27.1 .56

Самое короткое письмо, если его можно так назвать, в архиве Ф.Н. Милькова от Абрамова сохранилось с 1965 года. Корреспондент пять лет уже работал на новом месте - Институте географии АН СССР.

Дорогой Федор Николаевич!

Искреннее благодарен за поздравления к Великому празднику и пожелания.

С уважением и любовью. Л. Абрамов 14.XI.65-20

Если в двух предыдущих письмах почерк Льва Соломоновича Абрамова ровный, мелкий, чистый, то в трех последующих, датируемых 1995 и 1996 годами, напротив, размашистый, неаккуратный, как бы «спешащий». Письмо 1995 года - письмо деловое, информация о судьбе рукописи статьи, посланной профессором Ф.Н. Мильковым в «Известия Академии наук. Серия географическая».

\section{Дорогой Федор Николаевич.}

Посылаю Вам два отзыва на статью «О естественных ландшафтах юга Русской равниныл»-A.А. Величко и С. В. Зонна. Печатать статью мы будем обязательно. Но, возможно, Вы захотите что-то исправить или ответить на замечания. Сделайте это не откладывая. Жду.

Как Вы живете, над чем работаете? Пииите. Буду рад.

Обещзанную рецензию на книгу мы ещзе не получили. Обязательно напомню рецензенту.

Статью трех авторов ${ }^{\prime}$ о Дивногорье возвращзаю. Eе печатает «Природа».

$$
\begin{array}{r}
\text { С глубокой симпатией } \\
\text { Абрамов } \\
28.3 .95
\end{array}
$$

P.S. С рецензией на Вашу статью мы немного задержались - был болен Сергей Владимирович Зонн.

В течение 1996 года (апрель, сентябрь, ноябрь) Лев Соломонович напишет воронежскому адресату три объемных письма и в каждом будет извиняться за долгое молчание. Содержание писем многоплановое - наряду с обсуждением традиционных профессиональных тем содержится немало личного, а главное - не самых лестных отзывов о своих коллегах. Такие места следовало бы в других случаях опустить, но персон этих уже нет в живых, а значит для полноты портрета мы решили оставить тексты писем без купюр.

Л. С. Абрамов после смерти Гавриила Дмитриевича Рихтера был единственным для Ф.Н. Милькова информатором о состоянии дел в Институте географии. Для профессора Ф.Н. Милькова такие сведения были необходимы. Информирован - значит вооружен. Апрельское письмо Л. С. Абрамова написано на 7 страницах размером школьных тетрадей очень плотным, неровным почерком.

\section{Дорогой Федор Николаевич!}

Получил Ваше письмо с упреком, что давно не даю о себе знать. А потом и прекрасную статью об Игоре Забелине 2. И я из нее понял, как много

\footnotetext{
${ }^{1}$ Ф. Н. Мильков, А. В. Бережной, В. Б. Михно. Донское Дивногорье // Природа, 1995, № 9, с. 33-44.

${ }^{2}$ Статья «Страницы творческой биографии Игоря Михайловича Забелина (1927-1986) опубликована в «Известиях РАН. Сер. географическая, 1996, № 4, но автору не суждено будет ее видеть.
} 
значения Bы придаете личным общуениям, прежде всего с единомышленниками и просто с симпатичными Вам людьми. Ни книги, ни статьи в журналах в полной мере этого не заменяют.

$K$ сожалению, я всегда недооценивал переписку. Много хлопот и в жизни, и в Институте, и в журнале. Даже сосредоточиться на чем-либо порой трудно. Приходится писать на очень разные темы. В частности, много сил заняли публикации с юбилеем Войны (обратили ли вы внимание на мою «Описание войны» в № 3 за 1995 год - за ней было не только знание предмета, но и кропотливая работаз 3 . Затем не простая статья о Х съезде РГО (Вы ее увидите в № 2)4

Но все-таки остаюсь в строю даже на старости лет по последней аттестациии получил ведущего. И это при том, что основной штат ИГАН за последние годы уменьшился почти в два раза (с 620 до 350 чел.). Это правда не считая контрактников, договорников, «дочерних» предприятий и т.д. Институт сейчас изменился до неузнаваемости: и люди, и темь, и структура. Правда большими стараниями удалось восстановить отдел физической географии во главе с Н. Ф. Глазовским - как группу разных лабораторий.

В. С. Преображенский с маленькой группкой при директоре занимается историей. Трудный он, хотя и талантливый, человек. И мешал - в силу характера - не только мне.

О Вашей статье. Прежде всего, Игорь был, наряду с Наумом Григорьевичем Фрадкиньм (он плох, хотя голова продолжает работать) не только моим единомышленником, но и настоящчим другом. Мы общались с ним как-то удивительно легко: и в жизни, и при взаимном обсуждении или рецензировании работ. Потеря для меня не восполнимая. Статья об Игоре Вам очень удалась. В ней и человек, и художник, и ученый-мыслитель. Тепла и ненавязчива по-видимому и Ваша с ним дружба. Подкупают и сами критические высказывания Игоря. Так жаль, что он не доверил тогда нашему Ученому совету.

Вашу статью редколлегия утвердила: пойдет, очевидно в № 4, над которым мы сегодня работаем. Когда я докладывал статью В.М. Котляков заметил, что в последнее время у нас часто появляется Мильков. Я ответил, что просто долгое время его не пускали.

По сути статьи. Я не то что не согласен с оценкой «Путешествие в глубь науки», мы по поводу этой брошюры - действительно единственным монографическим выступлением об Андрее Александровиче - много спорили с Игорем. И не то, что он плохо его знал: слушал его семинар для аспирантов в МГУ, работал с ним в БСЭ леко не сразу Игорь осознал, что именно Григорьев - центральная фигура в развитии географической мысли на длительном отрезке развития нашей науки. Но потом он все расставил на свои места и в книге, и в ряде публикаций в «Известиях». Правы $\mathrm{Bbl,} \mathrm{что} \mathrm{создать} \mathrm{книгу} \mathrm{об} \mathrm{Андрее} \mathrm{Александрови-}$ че должны его ученики. Начал было такую книгу Г.Д. Рихтер, написал свыше 100 стр. (книгу он замыслил как биографический очерк), но ушел из жизни. Я довел до конца только несколько журнальных публикаций (у нас, в «Геогр. школе», в "Земля во Вселенной», в «Вестнике» $\left.{ }^{6}\right)$. Написал главу для сборника «Отечественные географы и путешественники», которую собрал В.А. Есаков (кажется она все-таки выйдет в этом году) ${ }^{7}$. Начал писать и книгу, заключил договор с «Просвещуением». Но в прочессе работы выяснилось, что их серия «Портреты ученых», адресуется не учителям, а как книга для чтения для учашиихя. Но так написать о теоретике мне не под силу - нужен талант как у Игоря. Именно в этой серии Игорь написал «Мудрость географии», свою рецензию на которую Вам посылаю. Наверное, Вы не видели, ни того, ни другого. Так работало «Просвещзение»их книги расходились по свочм каналам (кстати, видели ли Bbl «Основы конструктивной географии», 1996 из библиотеки учителя?). А у нас в Институте большой поддержки в создании книги я не нашел. В свое время Иннокентию Петровичу ${ }^{8}$ не слииком понравились два варианта книги об ИГАН, которую мы собрали (первую с Л.Г. Каманиным). Получилась история григорьевского института. (не читается) не очень замечал юбилеи ИГАН (70 и 75 лет), хотя мы договаривались с ним, он хотел книгу о перспективах, но это совсем другое, сосре-

\footnotetext{
${ }^{3}$ Автор письма имеет ввиду свою публикацию в «Известиях РАН» [1].

${ }^{4}$ Статья Л.С. Абрамова посвящена 150-летию со дня организации Русского географического общества [2].

${ }^{5}$ БСЭ - Большая советская энциклопедия.

${ }^{6}$ Имеется ввиду Вестник АН СССР.

${ }^{7}$ Сборник статей под названием «Творцы Отечественной науки. Географы» под редакцией В.А. Есакова опубликован издательством Агор в 1996 году. Статья Л.С. Абрамова «Андрей Александрович Григорьев (1883-1968)» на страницах $439-455$.

${ }^{8}$ Иннокентий Петрович Герасимов - директор ИГАН после А.А. Григорьева с 1951 по 1985 год.
} 
доточить все внимание на памяти. Очень активна Римма Петровна Герасимова 9 . Наконеи, инициативу с работами по истории географии стал перехватьлвать В.С. Преображенский. Тем не менее книга об Андрее Александровиче - мой моральный долг. Хотя, к сожалению, многие мои замысльл, и подчас не по моей вине, пока остались не реализованныли.

Федор Николаевич! Наверное мог бы быть Вам полезен - прислать какие-то институтские книжки или книжки «Открытоого (народного) университета». Там много наших авторов и книжечки эти у нас не продаются. Или Вы с ними знакомы по каким-то другим каналам? Пишите.

Очень цуеню наши контакты и Ваши публикации. С искренней симпатией Ваши Л. Абрамов 13.4.96

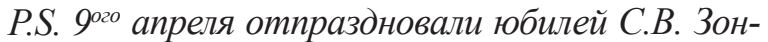
на. В свои 90 лет он плодовит, активен, даже по хорошему задирист (см. статью в № 2). В мае (15-го) исполняется 90 лет М.И. Львовичу. Даем статью о развитии географического направления в гидрологии Н.И. Коронкевича (персоналий о живущчих мы стараемся не давать).

Поражает плодовитость 87-летнего Эдуарда Макаровича ${ }^{10}$. Так что есть на кого ровняться.

Пройдет май и лето 1996 года и Л.С. Абрамов направит в Воронеж письмо-отчет для Федора Николаевича Милькова. В нем он сосредоточит внимание в основном на своих институтских делах и работе в журнале «Известия РАН. Серия географическая.

\section{Дорогой Федор Николаевич!}

Снова давно Вам не писал. Но вспоминаю вас все время и притом по самым разным поводам. Главный из них, конечно, Ваши статьи. Посылаю оттиски прошлогодней и вырезку из чистьх листов № 4, который вот-вот придет в Воронеж. Как видите, я с интересом и симпатией отношусь и к Вашему творчеству, и к текстам. Конечно, плохо, что гранки статьи об Игоре редакичия во-время не послала автору. Но не было времени, да и вопросов не возникало.

Второй повод - подготовка к юбилею Андрея Александровича (точнее, его статьи о комплекcax 1926 г. и закона периодической зональности) ${ }^{12}$. Знаю, что определенную активность проявляет B. C. Преображенский, что он с Вами переписывался (или перезванивался) - готовит он вместе с А. В. Дроздовым доклад о развитии школь А. А. Григорьева. Немного ревную: он знает, что и А. А. Григорьевым, да и иколами занимаюсь я. Так что немного ревную. Впрочем, это не в первый раз. С чем я выстууплю на юбилейной сессии пока не решил, м.б. с обзором трудов А. А. по истории.

Третья. Подал заявку на грант РФФИ - «Научные иколь академической географии» на $1997-$ 1998 годы. Конечно, какие-то ассоцчиации с Вашей вузовской географией при этом возникают. Когда-то хотел поспорить. Школьл я трактую несколько по иному. Но книга Ваша куда-то затерялась. В прочессе работь конечно вернусь к ней.

Четвертое. Отдал на машинку статью «Основные вехи геогр. описания России». В чем-то опираюсь на материаль книжки 1972 и других моих публикаций (поминаю в ней и среднемасштабное страноведение воронежцев). Но и осмысление несколько иное, и о перспективах есть, что сказать. Да и просто многие историю нашей науки знают плохо, начиная от президента Лаврова (немного лягнул его за это в отчете о съезде РГО в № 2 «Известий». Собираюсь публиковать у них в «Изв. РГО».

Пятое. Только что вышел сборник «Наука и ученыле России в годы Вел. Отеч. войны» (Наука). В весьма титулованной компании авторов я.

Шестое. Кончаю (вернее передельваю) статью «КЕПС-СОПС-география - природнье ресурсы». Писал ее к юбилею КЕПС ${ }^{13}$, выступал с ней с докладом. Но сборник у них рассыпался.

Вот и отчет. Конечно, это не письмо. Чувства у меня к Вам далеко не столь формальнь. Очень

\footnotetext{
${ }^{9}$ Она и несколько сотрудников Института географии опубликуют книгу «Иннокентий Петрович Герасимов. 1905-1985». М.: Наука, 1995, что станет в известной степени раздражителем к написанию монографии Т. Д. Александровой, посвященной А. А. Григорьеву [3, с. 8].

10 Эдуард Макарович Мурзаев.

${ }^{11}$ Автор письма, по-видимому, не точен. Речь идет о подготовке не к юбилею А. А. Григорьева, а к Григорьевским чтениям, состоявшимся в ноябре 1996 года.

${ }^{12}$ Имеется ввиду статья «О естественных ландшафтах юга Русской равнины», по которой рецензентами выступали А. А. Величко и С. В. Зонн, опубликована в «Известия РАН. Серия географическая», 1995, №5, с. 5-18.

${ }^{13}$ КЕПС - Комиссия по изучению естественных производительных сил России при Академии наук. Инициатива ее организации принадлежит В.И. Вернадскому и группе крупных ученых страны. Время организации - 1915 год. Структура КЕПС состояла из нескольких десятков отделов, специализировавшихся на изучении природных ресурсов и способах их рационального использования. В 1930 году произошло преобразование КЕПС в Совет по изучению производительных сил (СОПС). Многие отделы КЕПС были преобразованы в институты Академии наук. Так, в 1930 году был создан геоморфологический институт, директором которого стал А. А. Григорьев.
}

Вестник ВГУ, Серия: География. Геоэкология, 2021, № 4, 126-134 
жаль, что упустил возможность побывать в Воронеже вместе с нашими экономами. Узнал очень поздно, да и дома не все было в порядке.

Жизнь у нас, как и у всех, трудная. В Академии нет денег - это ударило и по ИГАН. Журнал идет интересный. Но тираж падает. Сам пока держусь в рабочем состоянии.

Искренне Ваш Абрамов 6.9 .96

Пройдет неполных два месяца после предыдущей корреспонденции, направленной профессору Ф.Н. Милькову, как Лев Соломонович напишет новое письмо с информацией о своих планах, институтских неурядицах, о коллегах-соперниках. Но, к сожалению, адресат с ним уже никогда не мог познакомиться.

\section{Дорогой Федор Николаевич!}

Давно не получал от Вас вестей. Даже не знаю получили ли Вы посланные мной отклики и письмо-отчет о моих делах и планах.

Сейчас многое уже изменилось. Готовлюсь $\kappa$ Григорьевским чтениям (на них у меня доклад о борьбе Андрея Александровича за фундаментальную географическую науку), поднял новые материаль, а главное - многое удалось переосмыслить. Теперь, пожалуй, действительно мог бы написать научно-популярную книгу. Очень ясно представилось развитие сюжета, и не только в области эволющии мысли, с рядом «взлетов», как вы пишите, но и с перипетиями жизни, действительно с борьбой, с сочетанием развертывания научных идей и их оформления со «строительством» организачионных форм их воплощения. Наверное, такой книгой (книжкой?) и займусь, особенно если РФФИ не удовлетворит мою заявку на грант «Научные школь в академической географии».

Сегодня В.С. Преображенский передал мне (в редакиию) Вашу "Бессрочную докторантуру». Многое мне в ней и понятно, и близко. Наверное сумеем опубликовать в «Григорьевских чтени$я x\rangle^{14}$. Хотя много интимного. Статья об Игоре Забелине (в № 4) была более динамичной и более общего звучания.

Не могу удержаться, чтобы не отметить, что Вы в последнее время как-то сблизились с Преображженским. Он сейчас проявляет большую активность, умеет мобилизовать данные не только архивов, но и живых свидетелей. Переменился и в отнотении к Вам. Стал признавать и школь в близком к моему пониианию. Но, к сожалению, «мягче» в отночении с людьми он не стал. А меня очень уж из многих позиций выбивал, впрочем как и других. Далеко не всегда ссылается, хотя к своим «приоритетам» весьма щепетилен. Умный «эгоиентрист». Простите, что немного посплетничал. Это у меня наболело. А в Вас давно чувствую единомышиленника. Весьма иеню Ваме дружеское участие.

С искренней симпатией Абрамов

1.11 .96

P.S. № 4 с Вашей статьей я передал Тамаре Забелиной. Она очень признательна Вам, просила адрес.

Если можно, часть оттисков (например, 10 из 25) я передам ей.

К сожалению, с ноябрьским 1996 года письмом Л.С. Абрамова с информацией о его научных замыслах адресату не суждено будет ознакомиться. Федор Николаевич скоропостижно скончается от стенокардического приступа двумя неделями ранее.

А Льву Соломоновичу так и не удастся реализовать свои претензии на приоритет о написании биографического произведения, посвященного академику А. А. Григорьеву.

Умную книгу о выдающемся географе, основателе первого академического Института географии академике Андрее Александровиче Григорьеве напишет жена В.С. Преображенского сотрудник ИГАНа Татьяна Давидовна Александрова [3].

\section{В. И. Булатов - уважаемый сибиряк}

Валерий Иванович Булатов - доктор географических наук, профессор, коренной сибиряк. Родился в городе Бодайбо Иркутской области. Родители Валерия Ивановича из рабоче-крестьянского сословия. Он выпускник геолого-географического факультета Томского государственного университета (1962). С 1964 по 1966 год обучался в аспирантуре на кафедре физической географии Воронежского госуниверситета. Научным руководителем у Валерия Ивановича был профессор Ф.Н. Мильков. Историю поступления в аспирантуру и яркие эпизоды ученичества В.И. Булатов детально описал в автобиографической статье в «Вестнике ВГУ» [4].

Как пишет Валерий Иванович: «Отношение ко мне Федора Николаевича было несколько иным, чем

\footnotetext{
${ }^{14}$ Статья «В бессрочной докторантуре у Андрея Александровича Григорьева», представленная в виде доклада при заочном участии в Григорьевских чтениях, опубликована в «Известиях РАН. Серия географическая, 1997, № 5, с. 61-66.
} 
к тем, что учился у него, слушал его лекции вживую...» [4, с. 123]. Действительно шеф часто ставил в пример научные успехи аспиранта Булатова нам молодым членам кафедры, не скрывая к нему доброжелательного отношения. Паренек с золотоносных приисков Бодайбо во многом преуспевал - научные конференции, статьи в журналы, полевые работы, контакты с представителями других наук о Земле. Кандидатская диссертация «Типы местности и природное районирование юго-востока Западно-Сибирской равнины (в границах Томкой области)» была досрочно защищена в 1966 году.

После окончания аспирантуры Валерий Иванович поработал во многих вузах (Томск, Омск, Барнаул) и академических учреждениях Сибири. С 2002 года «осел» в Югре, преподает в Югорском государственном университете с момента его основания.

Профессор В.И. Булатов автор более 350 научных публикаций, в том числе 20 монографий, аналитических обзоров, препринтов, учебных пособий. Область профессиональной деятельности - естественно-научные, прежде всего эколого-географические, георадиоэкологические, ландшафтные исследования регионов и городов Западной Сибири, оценка изменений природной среды в условиях современного природопользования, ландшафтное и тематическое картографирование. Он основатель школы регионального ландшафтного анализа и геоэкологического синтеза.

Работая в Сибири, Булатов изредка направлял в Воронеж своему научному руководителю поздравительные открытки, приветы от общих знакомых, а изредка, как участник конференций, приезжал в Воронеж.

Последняя встреча с профессором Федором Николаевичем Мильковом состоялась у В. И. Булатова накануне его защиты докторской диссертации. Он посетил Федора Николаевича, чтобы получить отзыв. При короткой встрече учитель, как вспоминает В.И. Булатов, - «нашел те слова, которые нужны были мне в столь ответственный момент» [4, с. 125].

Об успешной защите Валерий Иванович сообщил Федору Николаевичу телеграммой в Воронеж. Но ожидаемую приятную новость о пополнении числа докторантов Воронежской научной ландшафтной школы адресату, к сожалению, не суждено было принять. Вскоре Булатов получил скорбное письмо: «Воронеж, 1 ноября 1996 г. Глубокоуважаемый Валерий Иванович! Сердечно поздравляем Вас с успешной защитой! К сожа- лению, Федор Николаевич уже не сможет разделить с нами эту радость - 15 октября его не стало. С уважением, А. Бережной [4, с. 125].

\section{Г.Е. Гришанков - талантливый неудачник}

Гришанков Григорий Евдокимович (1918-1997) - уроженец Смоленской губернии. В течение 1934 1949 годов окончил два учебных заведения: Керченский горно-металлургический техникум (19341938) и Крымский государственный педагогический институт (1946-1949). По первой специальности проработал восемь лет (1938-1946) в Магаданской области техником-обогатителем оловянной руды. После окончания педагогического института с 1949 по 1956 год работал учителем географии в средней школе города Алушта. В 1956 году поступил в заочную аспирантуру к профессору Ф.Н. Милькову и одновременно до 1960 года работал преподавателем на кафедре физической географии Воронежского государственного университета.

Во время работы на кафедре Григорий Евдокимович занимался научной тематикой в двух направлениях. Как аспирант-заочник он разрабатывал тему кандидатской диссертации «Природа и ландшафты Восточных Яйл Крыма», которую защитил в 1958 году, а как сотрудник вуза участвовал в выполнении кафедральной тематики. Г.Е. Гришанков соавтор коллективной монографии «Физико-географическое районирование Центральных Черноземных областей» под редакцией Ф.Н. Милькова (Воронеж, 1961). На основе полевых исследований в бассейне Верхнего Дона и Оки Григорий Евдокимович напишет 3 главы монографии - Верхнеокский физико-географический район, Суджанский и Придонской известняково-карстовый.

Нам в 1959 году довелось слушать лекции Григория Евдокимовича по курсу «Методика преподавания географии». Мои студенты-однокурсники обращали внимание на оригинальность подхода лектора к анализу рассматриваемых проблем. Г.Е. Гришанков легко находил темы дискуссий. Научные диспуты были его страстью. Там, где в научных теориях и гипотезах имели место хотя бы небольшие противоречия или неточности, там Г.Е. Гришанков находил интерес к поиску истины.

В 1960 году Г.Е. Гришанков вернулся в Крым. Изредка приезжал в Воронеж. В 70-х годах задумал выполнить докторскую диссертацию, рассчитывая на поддержку сотрудников Института географии АН СССР. Но как показали дальнейшие события, намерения не реализовались. Была опубликована статья в «Известиях Академии наук. Серия географическая», где актуализирована идея 
зональности материков в зависимости от их высотных ступеней [5].

Последнее посещение Воронежа Григорием Евдокимовичем относится к началу 90-х годов. Не регулярно писал письма профессору Ф. Н. Милькову. Последняя его корреспонденция написана после ухода из жизни руководителя кандидатской диссертации, коллеги и ровесника.

В письме Г. Е. Гришанков делится своими неудачами публикационной активности.

Многоуважаемые Федор Николаевич и Серафима Артемовна!

Давно я Вам не писал, хотя желание написать все время было где-то в душе.

Недавно в беседе со своими учениками я по их просьбе дал краткую характеристику научныл трудам ведуших географов СССР ХХ века. При этом я старался выделить те находки, то новое, что, по моему мнению, останется надолго как научныле открытия и научные обобщцения. По этому критерию Вы Федор Николаевич обошли многих своих современников, таких, например, как Исаченко А.Г., Преображенского В.С., Солнщева Н.А., Гвоздецкого Н.А. и многих других. Такое явление на мой взгляд объясняется Вашей исключительной трудоспособностью и трудолюбием, и громадной интуицией. Ваша интуищия помогла Вам не подменять географию ни системологией, ни экологией, как это наблюдается в трудах многих географов. Все это позволило мне гордиться тем, что я Ваш ученик. Я многому научился, когда работал в Воронежском университете и позже, изучая все новые и новые Ваши работы.

Вкратие сообщу некоторые сведения о себе. После двух инфарктов мое здоровье кардинально ухудшилось. На протяжении трех последних лет я или болею, или между болезнями занимаюсь научной работой.

То учебное пособие, которое я в свое время посылал Вам, мне в Москве напечатать не удалось, так как издательство учебной литературы было закрыто, а моя рукопись (2 экз.) была потеряна или украдена. Три года назад я послал ее в Киев на конкурс учебников и учебных пособий в Фонд Сороса. Она прошла все три ступени конкурса с великолепныли отзывами, но ее украиниьь не печатают так как она написана на русском языке.

Лет пять тому назад я задался вопросом как литосфера влияет на географическую оболочку?

Для того, чтобы ответить на этот вопрос мне пришлось написать монографию объемом 25 издательских листов под названием «Литосфера: структура, функиионирование, эволюиия». Ее я тоже послал на конкурс, а дальше ничего неизвестно...

С глубоким уважением Гриманков

На почтовом штампе Симферополя отмечена дата-4.11.96.

Однако к счастью автора и географической научной общественности тревоги Григория Евдокимовича были напрасными. Учебное пособие «Введение в физическую географию. Предмет и метод» было опубликовано в Киевском издательстве «Знания» в 2001 году, спустя четыре года после его смерти.

Не затерялась и рукопись «Литосфера». Высоко нравственные ученики и друзья Г. Е. Гришанкова смогли найти варианты опубликовать учебное пособие - монографию в Симферопольском издательстве «Оригинал-М» в 2008 году.

Превосходная книга была подготовлена к печати учениками автора и коллегами с благодарностью. Здесь будет не лишним упомянуть всех их поименно - Е. Позаченюк, Г. Скребец, Е. Ергина, О. Никуленко, Е. Кудрянь, А. Магаррамонов, В. Михайлов. Такие поступки заслуживают подражания.

Э.М. Мурзаев - давний знакомый

Мурзаев Эдуард Макарович (1908-1998) - уроженец Симферополя. Выпускник Ленинградского государственного университета. Сразу после окончания вуза в 1930 году он связал свою научную деятельность с Институтом географии АН СССР. Его научные интересы находились в области физической географии, страноведения, истории географических исследований и топонимики [6].

Первое знакомство с профессором Ф.Н. Мильковом состоялось в послевоенные годы, когда Федор Николаевич стал часто посещать Институт географии, поступив в заочную аспирантуру к академику А. А. Григорьеву.

Долгие годы контакты Ф.Н. Милькова и Э.М. Мурзаева ограничивались обменом почтовой корреспонденцией. По короткой записке на почтовой открытке, адресованной Федору Николаевичу, можно предположить, что между ними сложились доверительные, сердечные отношения. В самом начале ноября 1996 года Э. М. Мурзаев пишет короткое письмо в Воронеж.

\section{Дорогой Федор Николаевич!}

Спасибо за хорошее письмо. Отвечаю с опозданием - второй месяц заточен в больнице из-за мучительной кожной болезни. Не знаю как выйти 
на волю. Передавайте мои наилучшие пожелания Вашей супруге. Будьте здоровы и как всегда трудоспособны.

Ваш Эд. Мурзаев

8.11 .96

Но, как и предыдущие письма и телеграммы Л. С. Абрамова, В.И. Булатова, Г.Е. Гришанкова, корреспонденция профессора Э. М. Мурзаева не могла быть адресату вручена.

\section{СПИСОК ЛИТЕРАТУРЫ}

1. Абрамов Л.С. Военно-географические описания - войскам // Известия РАН. Серия географическая, 1995, № 3, с. 90-102.

2. Абрамов Л. С. Юбилейный съезд географического общества // Известия РАН. Серия географическая, 1996, № 2, с. 7-21.

3. Александрова Т.Д. Академик Андрей Александрович Григорьев. Жизнь и научное творчество (18831968). Москва: Издательство «КМК», 2011. 416 с.
4. Булатов В.И. Мой учитель, наставник - Федор Николаевич Мильков // Вестник Воронежского государственного университета. Серия: География. Геоэкология, 2019, № 3, с. 121-126. DOI: https://doi. org/10.17308/geo.2019.3/2344

5. Гришанков Г. Е. Ландшафтные уровни материков и географическая зональность // Известия РАН. Серия географическая, 1972, № 4, с. 4-12.

6. Тишков А.А., В.Э. Мурзаева. Пространство, время и люди - главные герои его жизни // Известия РАН. Серия географическая, 2008, № 2, с. 132-137.

Конфликт интересов: Авторы декларируют отсутствие явных и потенциальных конфликтов интересов, связанных с публикацией настоящей статьи.

Поступила в редакцию 18.10.2021

Принята к публикации 23.11.2021

DOI: https://doi.org/10.17308/geo.2021.4/3761

\title{
Correspondence Not Delivered To the Addressee
}

\author{
S. V. Fedotov ${ }^{凶}$, V. I. Fedotov \\ Voronezh State University, Russian Federation \\ (1, Universitetskaya Sq., Voronezh, 394018)
}

\begin{abstract}
The purpose of the article is to acquaint the Russian geographical community with new biographical materials about the relationship between Professor F.N. Milkov and some famous Russian geographers. October 15, 2021 was a quarter of a century since the death of Professor F.N. Milkov. The authors of the article used reliable sources stored in the Professor's personal archive: long-term correspondence with L.S. Abramov and E.M. Murzaev of the Institute of Geography, the first postgraduate student and colleague in the 60s G.E. Grishankov, occasional contacts with Prof. V.I. Bulatov. The information presented in the article is published for the first time. The life experience of creators of science shows that when unrealistic conditions of direct contact are created, an epistolary style is actively used. Postal items remain the only collection in the archives of scientists where reliable materials of their personal relationships are preserved. F.N. Milkov corresponded for many years with many renowned national geographers. This article focuses on the four authors of correspondence that were not delivered to the addressee due to his death.
\end{abstract}

Key words: correspondence, letters, telegram, monograph, textbook, colleagues, institute.

For citation: Fedotov S. V., Fedotov V.I. Correspondence Not Delivered To the Addressee. Vestnik Voronezskogo gosudarstvennogo universiteta. Seria: Geografia. Geoekologia, 2021, no. 4, pp. 126-134. (In Russ.) DOI: https://doi.org/10.17308/geo.2021.4/3761

(C) Fedotov S. V., Fedotov V.I., 2021

$\bowtie$ Sergey V. Fedotov, e-mail: fsv777@yandex.ru

The content is available under Creative Commons Attribution 4.0 License. 


\section{REFERENCES}

1. Abramov L. S. Voenno-geograficheskie opisaniya voyskam [Military-geographical descriptions - to the troops]. Izvestiya RAN. Seriya geograficheskaya, 1995, no. 3, pp. 90-102. (In Russ.)

2. Abramov L.S. Yubileynyy s"ezd geograficheskogo obshchestva [Anniversary Congress of the Geographical Society]. Izvestiya RAN. Seriya geograficheskaya, 1996, no. 2, pp. 7-21. (In Russ.)

3. Aleksandrova T.D. Akademik Andrey Aleksandrovich Grigor'ev. Zhizn' i nauchnoe tvorchestvo (18831968) [Academician Andrey Alexandrovich Grigoriev. Life and scientific creativity (1883-1968)]. Moskow: Izdatel'stvo «KMK», 2011. 416 p. (In Russ.)

4. Bulatov V.I. Moy uchitel', nastavnik - Fedor Nikolaevich Mil'kov [My teacher, mentor - Fyodor Nikolaevich Milkov]. Vestnik Voronezhskogo gosudarstven-

\section{Федотов Сергей Владимирович}

кандидат географических наук, заведующий кафедрой рекреационной географии, страноведения и туризма Воронежского государственного университета, г. Воронеж, Российская Федерация, ORCID: 0000-00024969-7166, e-mail: fsv777@yandex.ru

Федотов Владимир Иванович

доктор географических наук, профессор кафедры рекреационной географии, страноведения и туризма факультета географии, геоэкологии и туризма Воронежского государственного университета, г. Воронеж, Российская Федерация, ORCID: 0000-0002-2753-4702, e-mail: deanery@geogr.vsu.ru nogo universiteta. Seria: Geografia. Geoekologia, 2019, no. 3, pp. 121-126. (In Russ.) DOI: https://doi.org/10.17308/ geo.2019.3/2344

5. Grishankov G.E. Landshaftnye urovni materikov i geograficheskaya zonal'nost' [Landscape levels of continents and geographical zoning]. Izvestiya RAN. Seriya geograficheskaya, 1972, no. 4, pp. 4-12. (In Russ.)

6. Tishkov A.A., V. E. Murzaeva. Prostranstvo, vremya i lyudi - glavnye geroi ego zhizni [Space, time and people are the main characters of his life]. Izvestiya RAN. Seriya geograficheskaya, 2008, no. 2, pp. 132-137. (In Russ.)

Conflict of interests: The author declares no information of obvious and potential conflicts of interest related to the publication of this article.

Received: 18.10.2021

Accepted: 23.11.2021

\section{Sergey V. Fedotov}

Cand. (Geogr.) Sci., Associate Professor, the Head of the Department of Recreational Geography, Country Studies and Tourism, Faculty of Geography, Geoecology and Tourism, Voronezh State University, Voronezh, Russian Federation, ORCID: 0000-0002-4969-7166, e-mail: fsv777@yandex.ruS

Vladimir I. Fedotov

Dr. (Geogr.) Sci., Professor of the Department of Recreational Geography, Country Studies and Tourism, Faculty of Geography, Geoecology and Tourism, Voronezh State University, Voronezh, Russian Federation, ORCID: 00000002-2753-4702, e-mail: deanery@geogr.vsu.ru 